\title{
Exhibiciones obscenas, vaguedad del término y colisión de principios constitucionales $^{1}$
}

\author{
Florencia Mariel Miranda ${ }^{2}$ \\ Universidad de Buenos Aires- Argentina
}

Revista Derechos en Acción ISSN 2525-1678/ e-ISSN 2525-1686

Año 5/Nº 14, Verano 2019-2020 (21 diciembre a 20 marzo), 679-696

DOl: https://doi.org/10.24215/25251678e371

ORCID: https://orcid.org/0000-0002-6907-1398

\section{Introducción}

El presente trabajo tiene por objeto analizar la vaguedad presente en el tipo penal de exhibiciones obscenas previsto en el Código Penal Argentino.

Pasaré a indicar que diferentes autores y la jurisprudencia nacional no desconocen la existencia de un defecto lógico en el término empleado por el legislador al momento de redactar el tipo penal en cuestión. Además de evidenciar este defecto lógico se considera necesario explicar en qué consiste y cuándo se presenta.

Así, resulta conveniente establecer los elementos del tipo a los fines de determinar cuándo se encuentra infringida la norma por la cual es obligatoria la sanción. Se sostiene que, el primer principio constitucional que resulta afectado por la presencia de esta vaguedad es el principio de legalidad, el

\footnotetext{
1 Trabajo elaborado en el marco de la asignatura "Sentencia Judicial y Argumentación Jurídica" y del Proyecto DeCyT UBA, 2018-2020, a cargo del Dr. Juan Pablo Alonso. Agradezco a John A. Carlin Sánchez, integrante del cuerpo docente.

2 Estudiante de la Carrera de Abogacía de la Facultad de Derecho de la UBA.
} 
cual establece que la ley debe ser anterior a la comisión del hecho que se pretende sancionar. Pero, si se trata de evitar esta lesión de una manera incorrecta, se estaría lesionando el principio constitucional de lesividad. Es decir que, al existir esta vaguedad en este tipo penal, también se produce la colisión entre los principios constitucionales de legalidad y de lesividad. No es posible solucionar esta colisión de manera sencilla, ya que ambos son principios constitucionales explícitos, lo cual implica que tienen la misma jerarquía. Ello genera que para determinar cuál de los dos pondera en un caso concreto es necesario analizar las situaciones fácticas del mismo.

Por lo expuesto, se tratara de encontrar una solución al problema que se suele generar por la imprecisión de este término. Propongo que es necesario un cambio en el sistema, pero que solo eso puede resultar insuficiente, ya que si se analiza en profundidad puede interpretarse que no solo la vaguedad del término es lo que torna incoherente el sistema.

\section{Vaguedad del término obsceno}

El artículo 129 del Código Penal Argentino establece que "será reprimido con multa de mil a quince mil pesos el que ejecutare o biciese ejecutar por otros actos de exhibiciones obscenas expuestas a ser vistas involuntariamente por terceros. Si los afectados fueren menores de dieciocho años la pena será de prisión de seis meses a cuatro años. Lo mismo valdrá, con independencia de la voluntad del afectado, cuando se tratare de un menor de trece años".

Como las leyes están expresadas en el lenguaje natural es común que presenten defectos lógicos como la vaguedad. La doctrina mayoritaria reconoce la existencia de la vaguedad del término obsceno. Es vago, en la medida en que no es posible determinar con precisión y anticipación qué acciones quedan subsumidas dentro del mismo. Este problema implica que no se sabe con precisión si un caso individual queda subsumido 
o no en el caso genérico establecido por una norma ya identificada. ${ }^{3}$

Según Carrió, existe vaguedad cuando “... la duda se origina en que no sé bien donde termina el campo de aplicación de la palabra $x$ y este caso parece hallarse en las proximidades de esos desdibujados linderos, cuya ubicación no puedo precisar". ${ }^{4}$

Este tipo penal solo prevé la existencia de una sanción para el caso en el que se produzca la exhibición, ya que "ejecutare o hiciere ejecutar" implica que es un delito que requiere que sea consumado para ser sancionado. Si bien, contempla dos tipos de víctimas, los mayores de edad y los menores, en el presente trabajo se tratarán de analizar la generalidad.

\section{II.A. Tipos de vaguedad}

Existen diferentes tipos de vaguedad, por lo que resulta necesario hacer al menos una breve explicación sobre en qué consiste cada uno de ellos, a los fines de determinar cuál es la presente en el término obsceno.

Vaguedad en términos polares: implica que existen dos extremos/polos, en uno de ellos la palabra es claramente aplicable, mientras que en el otro no es aplicable. El problema es que cada polo se va transformando gradualmente en el otro, provocando la incertidumbre de si en un caso subyacente en la zona de penumbra, que se genera entre los extremos, la palabra es aplicable o no. Ejemplos: alto/bajo; claro/oscuro, etc.

Vaguedad combinatoria: se produce cuando hay pluralidad de propiedades relevantes, pero no se determina con precisión cual es la cantidad de estas y en que intensidad deben estar presente para que ese caso quede comprendido dentro de ese término. Se sabe que se deben cumplir condiciones, pero

3 A Aonso, Interpretación de las normas y el derecho penal, $1^{\text {a }}$ ed., $1^{\text {a }}$ reimp., Cuidad Autónoma de Buenos Aires: Del Puerto, 2010, p. 59.

4 Carrió, Notas sobre derecho y lenguaje, 4ta ed., Abeledo Perrot, Buenos Aires, 1990, p. 31. 
cuales son estas y como deben darse, queda sujeto a los cambios de la sociedad. Ejemplos: religión, juego, etc.

Textura abierta del lenguaje: es imposible que el legislador anticipe toda conducta pasible de ser sancionada para poder legislar al respecto. Es inevitable que con los cambios que se producen en la sociedad aparezcan nuevos casos en los que no se dilucide con facilidad si el término es aplicable o no. Este tipo de vaguedad es imposible de eliminar por completo, pero es posible solucionarlo en cada caso en concreto.

En el presente trabajo se sostiene que el término "obsceno" se trata de una vaguedad combinatoria, ya que no se sabe con exactitud cuál es la pluralidad de condiciones relevantes que deben ser cumplidas para que ese caso quede comprendido dentro del término obsceno. Además, solo se sabe que dichas condiciones dependen de los valores protegidos por la sociedad al momento de realizado el hecho.

Si buscamos propiedades relevantes en el tipo, sería la exposición de lo sexual sin el consentimiento del espectador de dicha exhibición. Pero no se aclara en qué intensidad debe darse la exhibición, ni qué parte del cuerpo al ser expuesta es considerada obscena. Por lo cual, la solución más sencilla, para aclarar este término seria que el legislador sancione una ley que lo aclare. Pero, como ello no ocurre y los jueces deben seguir dictando sentencias, se sigue realizando la interpretación de este tipo abierto.

Según Alston la vaguedad combinatoria se "deriva de la indeterminación en torno a qué combinación de condiciones es necesaria o suficiente para la aplicación del término".5 Dichas condiciones varían al igual que lo hacen los valores jurídicos considerados valiosos en la sociedad. Según Alonso, no existe "una utilización relativamente estable para esta palabra". ${ }^{6}$ Esto la torna vaga, ya que su contenido depende de la concepción que la sociedad tenga respecto a este en un momento determinado.

5 Alston, Filosofía del lenguaje, Alianza Universidad, Madrid, 1974, pp. 125 y ss.

6 Alonso, op. cit., p. 61. 


\section{II.B. Bien jurídico protegido}

En lo referente al bien jurídico protegido, la doctrina se encuentra dividida. Mientras algunos autores y jurisprudencia sostienen que es el pudor público. ${ }^{7 / 8}$ Otros sostienen que es el pudor individual. ${ }^{9}$

Según este trabajo, lo que se pretende proteger es al individuo, el derecho que tienen las personas a no ser expuestas a situaciones que le puedan resultar lesivas en cuanto a su sexualidad.

La doctrina suele considerar que todo lo relacionado con lo obsceno está contemplado por los artículos 128 y 129 del Código Penal. Pero, en realidad, el articulo 128 prevé la sanción a la pornografía estableciendo como verbos típicos "produjere, financiare, ofreciere, comerciare, publicare, facilitare, divulgare o distribuyere", pero aclara que solo es sancionada esta conducta cuando la víctima es un menor de edad. En cambio, el tipo penal previsto en el artículo 129 contempla un tipo general y lo respectivo a los menores es una especie del tipo.

Según Romero Villanueva y González Garrido, el bien jurídico protegido es el pudor público. Además, consideran que lo obsceno depende del tiempo, del lugar, y resulta que se trata de un concepto dinámico y variable de lo que se extrae la imposibilidad de utilizar una definición unívoca. ${ }^{10}$ Esto es lo que realmente pasa, ya que el juez al momento de determinar si el término es aplicable o no tiene en cuenta los criterios de aplicabilidad vigentes en el sistema presente.

Ante la pregunta de ¿qué es obsceno? las respuestas pueden ser múltiples.

7 Publicado en: LA LEY1980-D, 883. Cita Online: AR/D0C/12289/2001 Báez, Julio C. - Arce Aggeo, Miguel Ángel. LA LEY2005-E, 94 - Supl. Penal 2005 (junio), 01/01/2005, 29

8 Cám. Nac. Crim. Y Corr., sala VII 20-10-92, “R., L.”, D. J. del 14-4-93.

9 C.C.C., sala VI, voto del doctor Zaffaroni, ED, 121-238; Juzgado en lo Correccional letra J, “G, L. M.", ED, 122-600.

10 D’Albora, “Código Procesal Penal de la Nación. Anotado. Comentado. Concordado.", Editorial Lexis Nexis, Abeledo-Perrot, Bs. As., 2005, p. 475. 
Según Creus es obscena la manifestación torpe de lo sexual que choca con los límites de esta expresión que tiene la sociedad. ${ }^{11}$ El elemento que aporta es que la sociedad tiene noción de límites para estas manifestaciones.

Los tribunales argentinos entienden por obsceno a "Lo torpe, impúdico, ofensivo al sentimiento público de pudor", ${ }^{12}$ "lo que tiende a excitar los instintos groseros y los bajos apetitos sexuales, ultrajando el pudor público o las buenas costumbre". ${ }^{13}$ Los términos utilizados producen más dudas que certezas, alimentando la imprecisión del término.

Según la Real Academia Española, a la cual se suele recurrir cuando se requiere alguna definición, la exhibición obscena es la "conducta que puede ser constitutiva de delito por la que se muestran los órganos sexuales a otro sin otra finalidad distinta a la propia satisfacción sexual". ${ }^{14}$ De esta definición académica, se puede deducir que, serían "exhibiciones de partes que deberían estar cubiertas y ello limitado a las que revistan un contenido sexual". ${ }^{15}$

\section{II.C. Contenido sexual}

En algunas sentencias, los tribunales argentinos han decidido que el contenido sexual es uno de los elementos del tipo penal de exhibiciones obscenas. Es decir, que han agregado mediante la jurisprudencia un elemento no previsto en la formulación normativa, el elemento del contenido sexual. Esto ha sucedido en la Causa No 967-01-00/15 "S. V., W. A. s/at. 129 y

\footnotetext{
11 Cfr. Creus, “Delitos Sexuales según la ley 25.087" J.A. 1999 - III - 807/15.

12 C.S.J.N., ED, 127-97; C.C.C., LA LEY, 7-1007; C.C.C., LA LEY, 23-331.

13 C.C.C., LA LEY, 99-1; C.C.C., sala II, LA LEY, 1986-D, 437; C.C.C. LA LEY, 14-337.

14 Real Academia Española consultado en [https://dej.rae.es/lema/exhibici \%C3 \%B3nobscena] el 27/11/2019.

15 Causa N 967-01-00/15 "S. V., W. A. s/at. 129 y otros CP"- Cámara de apelaciones en lo Penal, Contravenciones y de faltas, p. 6. Consultado en [http://public.diariojudicial.com/doc umentos/000/067/925/000067925.pdf] el 27/11/2019.
} 
otros CP" ${ }^{16}$ En este fallo de 2016, los hechos ocurridos fueron que un hombre, producto de la ira del momento y las discusiones con su vecino, exhibió sus genitales estando en la puerta de su departamento. En este caso la Cámara entendió que no era posible subsumir la conducta de este hombre dentro del término obsceno, en la medida en la que fue una simple exhibición careciente de contenido sexual, considerando atípica su conducta.

Al establecer que se exige la existencia de contenido sexual en la exhibición, queda en evidencia que se trata de un delito doloso y como tal, esto implica que debe haber voluntad de realizarlo. "El dolo es el conocimiento de todos los elementos del tipo y la voluntad de realizarlos". ${ }^{17}$ Esto debe estar presente al momento que se comete el hecho. ${ }^{18}$

Pero al existir la imprecisión en el término, no es posible saber fehacientemente con anterioridad a la realización del hecho todos los elementos del tipo objetivo. Por ello, sería posible alegar que esto vuelve atípica la conducta por tratarse de un error de tipo, pero debería demostrarse que este error es invencible, cosa que resultaría muy difícil si se exponen los órganos reproductivos, aunque hemos visto que depende de la intención con la que esto se hace.

Es importante la intencionalidad, ya que según la jurisprudencia, si la exhibición no tiene contenido sexual el posible infractor quedará absuelto. En el año 2002, en el Obelisco, se tomaron fotografías con fines artísticos de personas completamente desnudas, para ello se habían concedido las autorizaciones correspondientes. En este caso, un abogado que presencio la exhibición y se sintió agraviado formulo una denuncia penal contra la autoridad que permito esto y contra el artista que

\footnotetext{
16 Ibídem, p. 9.

17 Donna, Derecho Penal. Parte General, capítulo VII "el tipo subjetivo en el delito doloso", Rubinzal Culzoni, p. 515.

18 Donna, Derecho Penal. Parte Especial, Rubinzal Culzoni, p. 550.
} 
propuso la idea. En su dictamen, el fiscal en lo correccional entendió que no existió la actitud dolosa por parte del fotógrafo y los participantes, por lo cual se desestimó la denuncia. ${ }^{19}$ En este caso no era una acción dolosa y no tenía contenido sexual, por lo que se consideró atípica la conducta.

\section{Interpretación}

Para la aplicación de la ley es necesaria la interpretación de la formulación jurídica porque ninguna ley se aplica sola, por lo cual es el juez el que debe valorar los hechos e interpretar para poder aplicarla. ${ }^{20} \mathrm{El} \mathrm{juez} \mathrm{tiene} \mathrm{el} \mathrm{deber} \mathrm{de} \mathrm{analizar} \mathrm{los} \mathrm{valores}$ considerados valiosos por la sociedad al momento de aplicar una sanción, ya que no solo él es parte de esa sociedad, sino que a su vez la representa. Pero, que este sometido casi plenamente a la interpretación de un juez en cuanto a que no se determina que conducta es obscena, lesiona el principio de legalidad.

La ley es general, ya que se debe aplicar a todas las personas. Además, es abstracta, ya que no enumera todos los casos posibles. Por ello, es necesario que el juez interprete la ley que es general, que haga una interpretación judicial, para poner sancionar en el caso concreto. Este tipo penal ha sido considerado un tipo abierto, ya que se encuentra supeditado a la interpretación de la doctrina y la jurisprudencia. ${ }^{21}$

Ningún tipo penal puede tener una descripción exhaustiva, el juez debe aplicar la valoración cultural, ${ }^{22}$ ya que el exceso de especialización puede llevar a la inaplicabilidad cuando aparecen nuevas concepciones.

\footnotetext{
19 Nota publicada en el diario “Crónica" el 09/04/02. Citado “Asociación pensamiento penal", Código comentado de acceso libre. "Exhibiciones obscenas" por Fabián Luis Riquert y Marcelo Alfredo Riquert, p. 8, cita 29.

20 Bidart Campos, "¿La inconstitucionalidad del delito de publicaciones obscenas?", en E. D. 127-98/99.

21 C.C.C., sala I, "Álvarez Insua, Carlos", JA, 1987-III-44; C.C.C, sala II, causa "Pérez, Sergio", rta el 21/11/1998.

22 CSJN, 29-9-87, “M, N, J. y otros”. E. D. 127-97/102.
} 
Existen otros antecedentes, como "Dellino, J.A. S/ Exhibiciones Obscenas", un caso de 1980 cuya sentencia es de cámara, al igual que el caso anterior. En este, no solo no se exigió la existencia de contenido sexual, sino que no se exigió que el delito haya sido consumado para castigarlo de igual manera. Para ello, se sostuvo que "delito de exhibiciones obscenas es formal, razón por la cual no requiere una efectiva ofensa al pudor sexual de personas espectadoras, siendo irrelevante para su consumación que el becho haya sido visto, pues basta con que exista tal posibilidad". ${ }^{23}$

\section{III.A. Conflicto ocasionado por la imprecisión del término obsceno}

La existencia de la incertidumbre del término obsceno implica poner en peligro el principio constitucional de legalidad. En tanto, este exige que cuando se trata de aplicación de las sanciones previstas en el código penal los controles de que este principio sea respetado deben ser más estrictos.

En función del principio de legalidad, principio explicito previsto en el artículo 18 del texto constitucional, el sistema debe dar las soluciones más coherentes posibles respecto de este para protección de las personas. Pero, la existencia de esta imprecisión torna al sistema incoherente, en la medida en que no se permite al posible infractor conocer con anterioridad a la comisión del hecho que al realizar la conducta típica, se hará merecedor de una sanción penal.

En la doctrina impuesta por la Comisión Interamericana de Derechos Humanos (CIDH), en los antecedentes "Castillo Petruzzi y otros vs Perú"24 (1999) y "Kimel vs Argentina"25

23 Fallo DELLINO, J.A. s/ EXHIBICIONES OBSCENAS, 1980. Consultado en [http://www. saij.gob.ar/exhibiciones-obscenas-sug0002622/123456789-0abc-defg2262-000gsoiramus] el 27/11/2019.

24 Consultado en [http://www.corteidh.or.cr/docs/casos/articulos/seriec_52_esp.pdf] el 28/11/2019.

25 Consultado en [http://www.corteidh.or.cr/docs/casos/articulos/seriec_177_esp.pdf] el 28/11/2019. 
(2008), para satisfacer el principio de legalidad, el tipo penal en análisis debe ser determinado en forma expresa, previa, precisa y cierta (determinada).

Según el principio de legalidad los requisitos de la ley penal son:

Previa: debe existir una ley sancionada con anterioridad al hecho cometido que está siendo considerado como delito. No se puede aplicar la ley de forma retroactiva en contra del imputado por el principio de irretroactividad de la ley penal.

Escrita: debe existir una ley sancionada por el órgano competente. Ello implica que no se puede utilizar la costumbre para imponer una sanción penal.

Estricta: es aplicable solo a los casos contemplados por esa ley. Se prohíbe la utilización de la analogía, es decir que, no se puede aplicar la misma solución prevista para una situación en particular para otros casos con características similares.

Cierta: las leyes sancionadas por el legislador deben ser precisas (mandato de certeza). La norma escrita debe determinar con certeza la conducta u omisión que es punible. La ley penal escrita debe determinar y delimitar la acción contraria a la norma. ${ }^{26}$

Pero, en el caso del delito de exhibiciones obscenas se incumple con el mandato de certeza que debe tener la ley penal, ya que utiliza un término vago, no determinando de forma cierta cuales son los actos considerados merecedores de la sanción penal. Además, si bien la ley está escrita de forma previa, su contenido no es establecido previamente a la comisión del hecho, sino que está sometida a una valoración posterior.

"Nadie puede ser condenado por acciones $u$ omisiones que en el momento de cometerse no fueran delictivos según el derecho aplicable". ${ }^{27}$ Únicamente las normas escritas con anterioridad al

\footnotetext{
26 Roxin, "Iniciación al Derecho Penal de hoy", Universidad de Sevilla, pp. 112 y ss.

27 PIoué, "Artículo9.Principiodelegalidadyderetroactividad",consultadoen[http://www.derecho. uba.ar/publicaciones/libros/pdf/la-cadh-y-su-proyeccion-en-el-derecho-argentino/009-piquelegalidad-y-retroactividad-la-cadh-y-su-proyeccion-en-el-da.pdf] el 28/02/2020.
} 
cometimiento del hecho pueden volver a su actor pasible de sanción, de esta manera en un Estado de Derecho se limita el poder coercitivo el Estado. En un Estado de derecho, existe la obligación de que las conductas que violan las normas estén tipificadas claramente para que, quien hace lo que la ley penal considera delito sepa que está violando la norma jurídica y haciéndose merecedor de una sanción. ${ }^{28}$

En un intento de evitar la producción de daño al principio de legalidad, y ante el riesgo a la seguridad jurídica que representa la imprecisión del término, en algunos casos se ha solicitado que se declare la inconstitucionalidad del tipo penal. ${ }^{29}$

Es necesaria la existencia de una ley penal que determine con precisión cual es la conducta sancionada, ya que en caso contrario se genera incertidumbre en la persona pasible de sanción. Si esto ocurre se pone en peligro la seguridad jurídica, ya que no se permite predecir previamente la aplicación de esta pena. $^{30}$

La ley no es cierta y previa en cuanto a que, su contenido significativo está sujeto a la valoración, o mejor dicho la interpretación que le dé el juez en el caso concreto teniendo en cuenta los valores que la sociedad pretende resguardar en un momento, cultura y contexto histórico determinado.

Algunos sostienen que si bien los límites del término son imprecisos, es comprendida por el común de la gente de manera suficiente que permite conocer con antelación que esa conducta es reprochable. ${ }^{31}$ Pero, no es posible afirmar esto en todos los casos, más aun teniendo en cuenta que en la sociedad actual hay múltiples culturas conviviendo.

\footnotetext{
28 C.C.C., sala VI, causa 16.994 "S.D.", rta. el 6/10/1988.

29 Fallo C., D. J. s/infr. art(s) 1292 párr, Exhibiciones Obscenas (agravado por la edad) CP (p/L 2303), 2017. Consultado en [http://public.diariojudicial.com/documentos /000/075/980/000075980.pdf] el 28/11/2019. En la página 4, alegato de la defensora oficial.

30 Cfr. Maurach \& ZIPF, Derecho penal. Parte General, Astrea, 1994.

31 Dictamen del procurador general en el fallo de la CSJN, 29-9-87. "M., N., J y otro" E.D. 127-97.
} 
Las acciones que estén dentro del ámbito de libertad son penalmente irrelevantes. Esto está previsto en el principio de reserva de ley, artículo 19 Constitución Nacional Argentina segunda parte in fine, en cuanto a que solo se puede limitar un derecho mediante una ley y todo lo que no está prohibido por esta está libre de reproche.

$\mathrm{Al}$ existir la incertidumbre sobre cual conducta o exhibición es considerada obscena, se podría alegar que el principio constitucional de legalidad impone que una conducta que acarrea sanción penal necesariamente debe estar determinada con antelación a la producción del hecho. Pudiendo llevar esto a la absolución del acusado, pero esto podría generar un problema peor. En tanto, absolver a una persona que cometió, quizás no un delito penal, pero si un hecho dañoso para terceros, sería injusto. En este caso entrarían en colisión dos principios constitucionales explícitos como son el principio de legalidad y el de lesividad.

\section{Colisión de principios constitucionales}

Si bien, quien causa el daño sigue teniendo el derecho a que se respete la garantía del principio de legalidad, la persona dañada tiene derecho también a que se respete el principio de lesividad. Ambos son derechos constitucionales que deben ser respetados, pero cuando estos colisionan es necesario determinar cuál debe ponderar.

En caso de que la víctima se trate de un menor de edad, resultaría evidente que prevalecería el principio de interés superior del niño previsto en instrumentos internacionales como en el artículo 3 inciso de la Convención sobre los Derechos del Niño. En este se prevé que los tribunales al momento de tomar una decisión en un tema que respecta a un menor, debe proteger el interés superior del niño.

En caso de no cumplir con la protección del principio del interés superior del niño, el Estado Argentino tendría sobre si responsabilidad internacional. Esto se debe a que, en la reforma constitucional que tuvo lugar en 1994, en su artículo 75 inciso 22, 
se otorgó jerarquía constitucional a los principales instrumentos internacionales referentes a los derechos humanos. Entre estos, está la Convención sobre los Derechos del Niño, es decir que el principio del interés superior del niño goza de jerarquía constitucional, al igual que el principio de legalidad y el de lesividad, pero como se mencionó, el incumplimiento de este principio acarrearía responsabilidad internacional del Estado Argentino frente a la comunidad internacional. Por ello, cuando la víctima del delito es un menor de edad, las sanciones suelen ser más concretas y severas. Ello implica que, en caso de colisión de principios, el interese superior del niño pondera por sobre los otros.

Pero, en caso que se trate de una víctima mayor de edad, establecer entre los principios de legalidad y de lesividad cual prevalece resulta más complejo. En estos últimos casos el delito suele ser desestimado por falta de contenido sexual o porque queda subsumido dentro de un delito más gravoso, como el abuso sexual. ${ }^{32}$

Del principio de legalidad se desprende el aforismo Nullum crimen, nulla poena sine praevia lege el cual establece que una persona no puede ser sancionada por un acto que no era considerado delito al momento de su comisión. En el caso de esta norma que es vaga, si bien la ley es previa, no permite entender con precisión cuales son los elementos necesarios del tipo para ser pasible de sanción. La valoración de estos actos es posterior a la realización de los mismos. Por ello, se podría alegar que como el contenido del término es posterior a la realización del hecho, no se esta está cumpliendo con el principio de legalidad, por lo cual se debería absolver al acusado.

La exigencia de la ley previa está prevista a su vez en instrumentos internacionales, como en el artículo 11 de la Declaración Universal de los Derechos Humanos; en el artículo 14 del Pacto Internacional de Derechos Civiles y Políticos; y en el artículo 9 de la Convención Americana Sobre Derechos humanos. En

32 Fallo L.D.J. | infr. art(s). 129, $1^{\circ}$ párr. Exhibiciones obscenas. Cita MJ-JU-M-44580-AR | MJJ44580. 
el caso de las exhibiciones obscenas, si bien la ley escrita es previa, el contenido significativo de esta no es previo, sino que está sujeto a la interpretación del juez posterior a su realización.

En estos casos los principios constitucionales que están en colisión son, por un lado el principio de lesividad, previsto en el artículo 19, el cual implica que nadie puede realizar acciones que lesionen derecho de terceros ni física, ni psicológicamente. Por el otro lado, el artículo 18, del cual se desprende el principio de legalidad, el cual implica que nadie puede ser sancionado, sino en función de ley cierta anterior al hecho del proceso. El principio de legalidad tiene como función limitar el poder punitivo del Estado, al evitar la aplicación de toda sanción penal que no respete estrictamente los requisitos que debe cumplir una norma penal.

Las exigencias que tiene el principio de legalidad permiten a la persona gozar una garantía para limitar el poder punitivo del Estado. El Estado es quien tiene el ius puniendi, el monopolio del poder sancionador, el cual lo expresa de la forma más fuerte posible a través de la aplicación del derecho penal. La última ratio del derecho penal implica que para que este sea aplicado, los demás medios deben haber fracasado y debe ser indispensable sancionar. En el caso de las exhibiciones obscenas, es evidente que es necesario sancionar, pero no han fallado otros medios para sancionar, por lo cual se podría concluir que existen otras soluciones posibles. Considero que el hecho de que esta conducta este tipificada como delito penal es lo que genera el problema principal que debe ser solucionado.

El propio sistema penal considera al delito de exhibiciones obscenas como un delito menor, cuando la víctima es un mayor de edad, en la medida en que la sanción que prevé para este es el tipo de sanción más leve, meramente una multa. Al menos después de todo lo expuesto, es posible considerar que al cerrar este tipo penal considerado abierto se puedan generar inconvenientes, pero que son necesarios.

Resultaría más idóneo proceder para la sanción de este prejuicio por la vía civil mediante una demanda por daños y 
perjuicios, al menos de esta manera, la sanción pecuniaria que puede imponer está vía puede garantizar un resarcimiento más efectivo y completo que, el que podría haber dado el sistema penal, ya que las herramientas con las que cuenta cada vía son diferentes y específicas. Lo que busca este tipo de sanción es obtener un resarcimiento económico por los daños causados a los terceros. El propio legislador al momento de imponer una sanción opto por considerar que el daño producido por una exhibición obscena no puede acarrear una sanción mayor que la pecuniaria. Por ello, se podría fácilmente deducir que es viable optar, para el resarcimiento de este daño, por la vía civil.

Al realizar este reclamo por vía civil, se estaría reservando la vía penal para los casos más graves, manteniendo la concepción del derecho penal como última ratio.

Pero, si se pretende que esta exposición siga siendo un delito penal, resultará necesario que el legislador realice dos cosas. Primero, que derogue la ley vaga eliminándola del sistema normativo. Segundo, sancione una ley más específica en cuanto a los elementos que se deben cumplir para que quede constituido este delito. Creando con este acto de derogación y posterior promulgación un nuevo sistema normativa, el cual seguirá perteneciendo al mismo orden jurídico que el sistema anterior. Pero, como en la mayoría de los casos, esto no es tan fácil como parece, ya que ni la propia doctrina ni mucho menos la jurisprudencia se atreve a determinar sin titubeos que parte del cuerpo al ser expuesta es merecedora de sanción. De un análisis de ambas se puede concluir que lo considerado obsceno es en el caso de las mujeres, los pechos, en particular los pezones y los órganos genitales de esta. En el caso de los hombres, solo la exposición de los genitales puede ser considerado obsceno, ya que aparentemente a los pezones masculinos no se asocia connotación sexual.

Pero la dificultad en la tarea legislativa de promulgar una formulación normativa también está en que, lo que es considerado obsceno depende de un contexto, una cultura y un momento histórico determinado. Lo considerado obsceno varia 
con cada sociedad, no es lo mismo lo que era considerado obsceno la década pasada que lo que es considerado obsceno en la actualidad. Basta con preguntarle a nuestros abuelos para confirmar que cuando ellos eran jóvenes, el solo hecho de que la mujer enseñase las piernas por sobre sus rodillas podía ser considerado provocativo y obsceno. Actualmente esto parece irrisorio, hasta en provincias tan conservadoras como continúa siendo Salta, en la actualidad se ha llegado a naturalizar que la mujer pueda enseñar las piernas, parte del pecho, los hombros, siempre y cuando no muestre el pezón o los órganos reproductivos. Por ello, cabe concluir que lo que actualmente la sociedad considera obsceno, en la próxima década puede no ser considerado como tal.

\section{Conclusión}

Como se ha analizado, el término obsceno es un término vago reconocido por la jurisprudencia y la doctrina, pero no se ha hecho más que mantener ese defecto lógico alegando que se trata de un tipo penal abierto. Que sea un tipo abierto implica que, cuando un caso se presenta ante el juez, este decidirá interpretando la norma, si esa conducta queda subsumida dentro del término obsceno o no.

Pero la existencia de esta imprecisión en el término obsceno, en tanto no sea solucionada, amenaza con afectar el principio de legalidad que debe respectar toda norma del ordenamiento jurídico, más aún cuando se trata de una norma penal.

Si bien, se podría alegar que existen ciertos límites previstos en la sociedad, en cuanto a que partes se pueden exponer sin ser sancionados y cuáles no. También es cierto que, la sociedad está formada por un grupo heterogéneo de personas, de las cuales no todas tienen los mismos "estándares" de moralidad.

Lo que es considerado obsceno queda a la valoración de un juez que debe interpretar los valores de la sociedad en su conjunto, lo cual no es tarea fácil. Los pocos autores que se atreven a reconocer cuales partes del cuerpo al ser expuestas 
son consideradas obscenas coinciden en que, exponer los órganos reproductivos se está cometiendo este delito. Pero, la jurisprudencia parece sostener, al menos por lo analizado, que ni siquiera la exposición de estos es determinante, agregando el elemento del contenido sexual.

Que exista un problema no implica que se pueda dejar impune a quien daña. Pero, al momento de sancionar el juez debe tener presente esta imprecisión e imponer penas en función del perjuicio causando.

La imprecisión y vaguedad del término obscenidad no permite al sujeto conocer con antelación si su conducta termina siendo contemplada por este tipo penal o no, afectando al principio de legalidad. La jurisprudencia lejos interpretar con precisión qué es lo que el legislador considera obsceno, lo único que ha hecho es alimentar esta imprecisión considerando simplemente que es un tipo penal sujeto a la interpretación. Es decir que, como se ha venido interpretando hasta el momento lo único que se ha hecho es seguir profundizando o reproduciendo la vaguedad combinatoria que presenta el término obsceno sin dar una solución definitiva a este problema.

Por todo lo expuesto es notoria la existencia del problema y que este necesita solución. Una solución posible es la propuesta en este trabajo. Cambiar la vía del reclamo para obtener una reparación del daño más integral que la que puede dar la vía penal es lo que parece más adecuado, al menos por el momento. El cambio en la vía, no solo permitiría obtener un resarcimiento más integral, sino que también le permitiría al ordenamiento jurídico argentino recuperar la coherencia perdida.

\section{Bibliografía}

Alonso (2010) Juan Pablo, "Interpretación de las normas y el derecho penal". $1^{a}$ ed. $1^{a}$ reimp. Cuidad Autónoma de Buenos Aires: Del Puerto.

Alonso, Juan Pablo (2018). Violación, aborto y las palabras de la ley, Editorial Pensar en Derecho, Buenos Aires. 
Alston, William (1974). Filosofía del lenguaje. Alianza Universidad, Madrid, 1974.

Congreso de la Nación (1921) Código Penal Argentino. Edición en línea. Buenos Aires, Argentina.

Bidart Campos, Germán J. (1999). “LLa inconstitucionalidad del delito de publicaciones obscenas?”, en E. D. 127-98/99.

Cámara de Apelaciones en lo Penal, Contravencional y de Faltas (2015). Causa No 967-01-00. S.V.W.A. s/at 129 y otros CP"- Apelación. Buenos Aires.

Carrió, Genaro (1990). Notas sobre derecho y lenguaje (4ta ed. Corregida y autenticada). Abeledo Perrot. Buenos Aires.

Continental. La Mirada Despierta (2015). "Usuarias del subte: "El acoso, el manoseao y las exhibiciones obscenas son algo habitual". En línea en: https://www.continental.com.ar/noticias/ sociedad/usuarias-del-subte-el-acoso-el-manoseo-y-las-exhibiciones-obscenas-son-algo-habitual/20151021/nota/2977372.aspx

Corte Interamericana de Derechos Humanos (2008) Caso Kimel vs Argentina. Sentencia de 2 de Mayo de 2008 (fondo, reparaciones y costas) Edición en línea

- (1999). Caso Castillo Petruzi y otros Vs Perú. Sentencia de 30 de Mayo de 1999 (fondo, reparaciones y costas. Edición en Línea

D’Albora, Francisco J. (2005). Código Procesal Penal de la Nación. Anotado. Comentado. Concordado, Editorial Lexis Nexis, Abeledo-Perrot, Bs. As.

Donna Edgardo Alberto (2014). Fundamentos - Teoría de la Ley Penal Editorial Rubinzal-Culzoni Editores, Buenos Aires.

Riquert F.L y Riquert Marcelo Alfredo (2013). "Exhibiciones Obscenas" Código Penal Comentado de Acceso Libre. Asociación Pensamiento Penal. En línea en: http://www.pensamientopenal.com.ar/cpcomentado/37957-art-129-exhibiciones-obscenas

Piqué, María Luisa (2020). "Artículo 9. Principio de legalidad y de retroactividad". Primer párrafo. Consultado en http://www. derecho.uba.ar/publicaciones/libros/pdf/la-cadh-y-su-proyeccion-en-el-derecho-argentino/009-pique-legalidad-y-retroactividad-la-cadh-y-su-proyeccion-en-el-da.pdf 